\title{
ANÁLISE RETÓRICA DAS MEMÓRIAS DE PASCHOAL LEMME ${ }^{1}$
}

DOI: http://dx.doi.org/10.1590/2236-3459/62180

\author{
Roberta Aline Sbrana \\ Universidade Estadual Paulista Júlio de Mesquita Filho, Brasil. \\ Marcus Vinicius da Cunha \\ Universidade de São Paulo, Brasil.
}

\begin{abstract}
Resumo
Este trabalho analisa as memórias de Paschoal Lemme, publicadas na década de 1980 contendo aspectos de sua vida e de sua atuação como educador entre os anos de 1920 e 1960. A metodologia utilizada é a análise retórica, fundamentada em Aristóteles e nas obras de Perelman e outros pesquisadores envolvidos na revitalização da retórica. Seguindo os parâmetros desse método, considera-se que todo texto publicado possui uma intencionalidade, sendo destinado a persuadir os leitores para a aceitação de uma ideia e para a adoção de condutas destinadas a manter ou modificar determinado estado de coisas. Esses parâmetros são aplicados às memórias de Lemme com o intuito de identificar as estratégias argumentativas utilizadas pelo autor perante sua audiência.

Palavras-chave: Paschoal Lemme, memória, análise retórica, educação brasileira.
\end{abstract}

\section{RHETORICAL ANALYSIS OF PASCHOAL LEMME MEMORIES}

\begin{abstract}
This study analyzes the memoirs of Paschoal Lemme, published in the 1980s containing aspects of his life and his role as an educator between the years 1920 and 1960. The methodology used is the rhetorical analysis, based on Aristotle and on the works of Perelman and some other researchers involved in the rhetoric revitalization. Following the parameters of this method, one can consider that all published text has an intentionality, being designed to persuade readers to accept an idea and to adopt behaviors so as to maintain or modify certain state of affairs. These parameters are applied to Lemme's memoirs in order to identify the argumentative strategies used by the author before his audience.

Keywords: Paschoal Lemme, memory, rhetorical analysis, brazilian education.
\end{abstract}

\section{ANÁLISIS RETÓRICA DE LAS MEMORIAS DE PASCHOAL LEMME}

\section{Resumen}

Este estudio analisa las memorias de Paschoal Lemme, publicadas en la década de 1980 que contiene los

${ }_{1}^{1}$ As pesquisas que originaram este trabalho foram subsidiadas por Fapesp e CNPq. 
aspectos de su vida y su papel como educador entre los años de 1920 y 1960. La metodología utilizada es el análisis de la retórica, basado en Aristóteles y las obras de Perelman, y otros investigadores que participan en la revitalización de la retórica. Seguiendo los parámetros de este método, se considera que todo el texto publicado tiene una intencionalidad, está diseñado para persuadir a los lectores para la aceptación de una idea y de adoptar conductas para mantener o modificar cierto estado de cosas. Estos parámetros se aplican a las memorias de Lemme con el objetivo de identificar las estrategias argumentativas utilizadas por el autor perante su público.

Palabras clave: Paschoal Lemme, memoria, análisis retórica, educación brasileña

\section{ANALYSE RHÉTORIQUE DES MÉMOIRES DE PASCHOAL LEMME}

\section{Résumé}

Cette étude analyse les mémoires de Paschoal Lemme, publiées au cours de la décennie de 1980, contenant les aspects de sa vie et de son rôle d'éducateur entre les années 1920 et 1960. La méthodologie utilisée est l'analyse rhéthorique, fondée sur Aristote et des oeuvres de Perelman et d'autres chercheurs impliqués dans la revitalisation de la rhéthorique. Selon les paramètres de cette méthode, il est considéré que tout le texte publié a une intentionalité, étant destiné à persuader les lecteurs à l'acceptation d'une idée et à adopter des comportements pour maintenir ou modifier certaines état de choses. Ces paramètres sont appliés à mémoires du Lemme afin d'identifier les stratégies argumentatives utilisées par l'auteur à son auditorie.

Mots-clés: Paschoal Lemme, mémoire, analyse réthorique, éducation brésilienne. 


\section{Introdução}

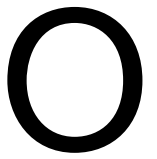

reconhecimento das narrativas memorialísticas como fontes válidas para a pesquisa historiográfica surgiu no cenário internacional no decorrer do século XX, obtendo sensível destaque nas décadas de 1960 e 1970, ocasião em que se desencadeou intenso debate sobre as relações entre história e memória (THOMSON; FRISCH; HAMILTON, 2006, p. 66). Esse movimento chegou ao Brasil nos anos de 1990, sem dispensar a consequente polêmica entre adeptos e críticos dessa metodologia de investigação (AMADO; FERREIRA, 2006, p. 9).

Dentre as manifestações favoráveis ao referido método, a literatura especializada registra o argumento de que a memória possui a vantagem de trazer informações que seriam inacessíveis por intermédio de outros recursos de pesquisa (LE GOFF, 2003, p. 419). Nessa vertente, a memória é vista como um "canal privilegiado" pelo qual os "questionamentos e as técnicas peculiares da literatura se transmitem à historiografia" (LEVI, 2006, p. 168). Dentre as objeções, alega-se que os dados advindos da narrativa memorialística são permeados pela subjetividade, uma vez que refletem o ponto de vista de alguém comprometido com o que descreve. O narrador elege, segundo intenções particulares, somente o que julga significativo para dar "coerência" a determinados eventos, tornando-se, desse modo, um "ideólogo de sua própria vida” (BOURDIEU, 2006, p. 184-185).

Uma solução possível para esta celeuma seria confrontar o relato memorialístico com outras fontes de semelhante valor documental. Tal saída, no entanto, não é suficiente para garantir a eliminação do fator subjetividade, se considerarmos que a verdade histórica é sempre uma versão de fatos pretéritos. Como bem assinala Le Goff (2003, p. 110), as "estruturas de poder de uma sociedade" orientam a história em sentidos diversos, determinando a construção dos registros do que ocorreu; todo documento deve ser cuidadosamente examinado, pois "nenhum documento é inocente".

Assim, o argumento que questiona o valor das memórias abrange praticamente todos os demais meios de reconstituição do passado. Para agir de maneira coerente e isenta, o pesquisador deve sempre investigar, da maneira mais precisa possível, a autoria das fontes com que trabalha e o momento histórico em que foram produzidas e publicadas. É nessa perspectiva que se apresenta a análise retórica como alternativa útil ao estudo de narrativas memorialísticas (SBRANA, 2016). Seus instrumentos teóricos e metodológicos envolvem o exame dos qualificativos (ethos) do autor de um texto - que é denominado orador - e o estudo do contexto de enunciação e veiculação das memórias; o discurso (logos) propriamente dito, ou seja, a trama argumentativa articulada pelo memorialista; e as disposições (pathos) intelectuais e emocionais dos leitores, a audiência a quem o autor se dirige.

Essa linha teórica é decorrente de Aristóteles e, mais recentemente, das obras de Chaïm Perelman e outros pesquisadores envolvidos na revitalização da retórica. Nessa abordagem não se busca formular juízos de valor sobre o autor e as teses por ele defendidas, mas desvendar as estratégias discursivas postas em ação em sua obra, considerando que todo texto que se torna público é imbuído de intencionalidade. Quem publica pode fazê-lo simplesmente para emocionar ou produzir entretenimento, mas os materiais qualificados como de natureza filosófica e científica são elaborados, via de regra, com o intuito de persuadir, mobilizar os leitores para a aceitação de uma ideia e, 
em última instância, para a adoção de condutas destinadas a manter ou modificar determinado estado de coisas (PERELMAN; OLBRECHTS-TYTECA, 2005, p. 7).

O presente trabalho busca contribuir para aperfeiçoar a análise retórica no campo das narrativas memorialísticas, focalizando a autobiografia de Paschoal Lemme (19041997), educador que atuou no Brasil entre os anos de 1920 e 1960. Os cinco volumes contendo as memórias e alguns documentos produzidos por ele foram publicados na década de 1980 pela Editora Cortez e pelo Instituto Nacional de Estudos Pedagógicos, INEP, órgão do Ministério da Educação e Cultura (LEMME, 1988a; 1988b; 1988c; 2004a; 2004b). Tal iniciativa foi importante para fazer de Lemme um autor - mais ainda, um ativista político - conhecido pelas novas gerações de educadores, bem como para difundir as suas teses sobre educação, todas elas declaradamente baseadas em preceitos marxistas.

Este trabalho tem a intenção de contribuir não só para ampliar a abrangência dos estudos retóricos - hoje bastante desenvolvidos em vários países, sob diversos enfoques e aplicados a vários objetos - como também para propiciar uma discussão, no campo próprio da historiografia, acerca dos fatores que elevam certos discursos memorialísticos ao patamar de fontes válidas para a pesquisa. No tocante a Lemme, especificamente, será oportuno discutir de que maneira a peculiar organização de sua narrativa auxiliou na projeção de certas teses educacionais no Brasil dos anos de 1980, ocasião em que foram publicados os volumes de suas memórias.

Para examinar o discurso de Paschoal Lemme, será útil considerar que os autores de textos pretensamente persuasivos necessitam inspirar credibilidade em seus leitores; seguindo o conselho dos antigos mestres de retórica, é importante "darem uma impressão favorável de suas pessoas, atraírem a estima, a benevolência, a simpatia de seu auditório" (PERELMAN; OLBRECHTS-TYTECA, 2005, p. 362). As informações que usualmente acompanham as publicações acadêmicas cumprem essa função, ainda que parcialmente, ao veicularem dados sobre a formação, o vínculo institucional e a produção dos autores, medida esta que produz uma imagem positiva de quem responde pela autoria do texto, podendo influenciar no julgamento dos conteúdos do próprio texto.

Quando se trata de memórias, é a narrativa dos fatos vividos que desempenha esse papel; memórias são formas privilegiadas de persuasão, pois a escrita dos acontecimentos influi no juízo dos atos praticados e das ideias defendidas, projetando certa imagem do narrador (ALBERTI, 2004, p. 34). Pode-se dizer, em suma, que o discurso memorialístico constitui um empreendimento dedicado à construção da imagem do autor, a qual obterá efeitos mais ou menos efetivos dependendo das circunstâncias históricas e das características dos leitores. A possibilidade de sucesso é ampliada quando o narrador emprega um discurso capaz de atingir o âmbito emocional da audiência, pois, como afirmam Perelman e Olbrechts-Tyteca (2005, p. 6), as emoções são determinantes na obtenção do objetivo maior da retórica, a "adesão dos espíritos".

Para Aristóteles (Retórica, II, 1378a20), são as emoções, ou paixões, o fator causal das mudanças em nossos julgamentos, influenciando diretamente na apreciação que fazemos dos fatos descritos, seja em um discurso oral ou escrito. Reale (2001, p. 195) define paixão como "perturbação da alma", algo que se vincula ao "corpo ou à parte da alma mais próxima da animalidade" e que, por isso, é de difícil controle. A arte da narrativa consiste na tentativa de controlar as paixões alheias, dando a elas um 
direcionamento. Por conterem o já mencionado fator subjetividade, as narrativas memorialísticas são especialmente propícias ao exercício dessa tentativa.

\section{O homem e sua missão}

Abrangendo de sua infância ao ano de 1982, Paschoal Lemme narra em suas memórias várias passagens de sua vida, com ênfase em sua atuação profissional e em seus posicionamentos políticos e educacionais. Um momento de sua trajetória é marcante: ainda criança, Lemme (1988a, p. 114) descobriu qual era a sua vocação - ser educador. Dali por diante, sua vida foi conduzida pelo interesse profundo por temáticas educacionais, o que o obrigou a enfrentar inúmeros obstáculos, especialmente no âmbito de sua família. Apesar das dificuldades, sua vocação era confirmada a cada dia, o que o fez persistir na luta para sua realização.

E foi vitorioso: formou-se no curso de magistério da Escola Normal do antigo Distrito Federal em 1924, ingressando em seguida no serviço público como professor. Assumiu, então, o propósito de mudar a educação para fazer do Brasil uma nação moderna, ideal que buscou realizar em associação íntima com os escolanovistas, compondo o movimento de renovação educacional que abrangeu vários estados da federação nos anos de 1920 e 1930.

Essa narrativa - a descoberta precoce da vocação docente, o enfrentamento de obstáculos, a obstinação por uma meta - revela a imagem de um homem imbuído de uma missão. No decorrer de suas memórias, Lemme constrói de si mesmo uma imagem messiânica, termo que remete precisamente à ideia de um propósito a ser cumprido por alguém que é movido por ideais inabaláveis. Essa autoimagem positiva torna-se inevitavelmente associada às teses políticas e educacionais por ele defendidas, as quais se beneficiam sobremaneira por serem oriundas de uma pessoa dotada de qualidades excepcionais.

A construção de uma imagem messiânica favorece angariar prestígio perante a audiência, que identifica na figura do indivíduo singular um conjunto de concepções a serem seguidas. Essa forma de articulação discursiva permite que as atitudes do orador assumam o caráter de superioridade perante outras, aumentando as chances de serem aceitas como necessárias (PERELMAN; OLBRECHTS-TYTECA, 2005, p. 345). Segundo os preceitos da análise retórica, o que opera nesse caso é a estratégia discursiva que consiste em transferir as qualidades de uma pessoa aos atos por ela praticados ou às teses por ela defendidas (idem, p. 341). Na narrativa de Lemme, a autoimagem messiânica do autor coopera fortemente com a aceitação de seu modo peculiar de relacionar educação e sociedade.

Essa estratégia argumentativa torna-se sensivelmente mais próxima do objetivo da retórica - a "adesão dos espíritos", como vimos acima - quando associada à mobilização de determinadas paixões; evidentemente, aquelas que favoreçam a imagem do narrador. Na Retórica (II, 1378a20), Aristóteles discorre sobre várias modalidades de emoções que podem auxiliar o orador a ampliar o poder de persuasão de seus argumentos, uma vez que, como também já vimos, as paixões são responsáveis por moldar o juízo da audiência acerca das teses que lhe são apresentadas.

Souza (2016) considera que algumas das paixões descritas por Aristóteles 
inspiram sentimentos "positivos", por transmitirem credibilidade ao objeto da narrativa, despertando na audiência impulsos de aproximação; outras seriam "negativas", no sentido de incentivarem disposições de contrariedade, afastamento. Sendo o narrador o tema central da narrativa memorialística, quanto mais paixões positivas forem a ele associadas, maiores serão as chances de os leitores depositarem crédito nas ideias por ele defendidas.

$\mathrm{Na}$ narrativa em que Paschoal Lemme assume papel messiânico, portador de uma vocação que o leva a enfrentar toda ordem de dificuldades, o sentimento que aflora com mais frequência é o que Aristóteles (Retórica, II, 1383a15) denomina "confiança", paixão definida como o "oposto do medo". Confiar significa acreditar que "as coisas que podem nos proporcionar segurança estão próximas", enquanto as "temíveis estão ausentes ou distantes". A pessoa que possui tal disposição perante sua vida angaria a credibilidade da audiência, que passa a ver as teses por ela defendidas como dignas de respeito, como algo em que se pode acreditar e, também, confiar.

\section{Atuação do missionário}

O envolvimento de Paschoal Lemme com as questões políticas da área educacional teve início na Associação Brasileira de Educação, $A B E$, à qual se filiou em 1926 por concordar com os princípios gerais defendidos pelos educadores que pretendiam renovar o cenário escolar brasileiro. Entre os anos de 1928 e 1930, participou da reforma do ensino empreendida por Fernando de Azevedo no Distrito Federal, a qual, segundo ele, apresentou "atividades criadoras" para a organização de uma nova escola (LEMME, 1988c, p. 34).

Em 1932, Lemme foi um dos signatários do Manifesto dos Pioneiros da Educação Nova, encarregando-se de recolher as assinaturas que consolidaram o polêmico documento. Foi nesse período que conheceu a filosofia marxista, a qual, dali por diante, passou a orientar as suas ideias e a conduzir os rumos de suas iniciativas em prol do ensino. Mesmo permanecendo "fora dos quadros do Partido Comunista", assumiu a condição de "intelectual de esquerda" (BRANDÃO, 2002, p. 883).

Embora integrasse o grupo dos chamados pioneiros da educação, Lemme afirma que ficou "praticamente sozinho contra a totalidade" de seus colegas, que não compartilhavam de suas ideias, o que não o impediu de continuar lutando por seus ideais (LEMME, 1988c, p. 209). Assim, atuou na reforma do ensino liderada por Anísio Teixeira entre 1931 e 1935, assumindo vários cargos e funções. Segundo a sua apreciação, mesmo cometendo "possíveis 'pecados' da 'americanização", foi aquela "a mais criativa, corajosa e também controvertida administração de ensino" ocorrida no país (LEMME, 1988c, p. 134).

A defesa das teses esquerdistas e a proximidade com os líderes comunistas fizeram com que Lemme se tornasse cada vez mais "solitário, 'estrangeiro' mesmo, entre os educadores liberais" (BRANDÃO, 1999, p. 109-110). Em 1936 e 1937, esteve preso sob a acusação de disseminar ideias comunistas; após ser inocentado, retornou à vida pública, mas continuou enfrentando obstáculos, pois o Estado Novo foi, desde o início, frontalmente contrário às suas concepções de sociedade. Em 1939, Lemme trabalhou no Instituto Nacional de Estudos Pedagógico, INEP, mas afastou-se do cargo em 1942 por discordar das diretrizes políticas do diretor Lourenço Filho. 
Pouco tempo depois, por indicação do amigo Francisco Venâncio Filho, foi designado para chefiar a Seção de Extensão Cultural do Museu Nacional, então dirigida por Heloísa Alberto Torres (LEMME, 1988c, p. 54). Concomitantemente, passou a atuar no Instituto Nacional de Cinema Educativo, onde, com o apoio de outro amigo, Edgar Sussekind, organizou o "maior número possível de filmes e diafilmes que viessem atender às necessidades do ensino primário, secundário e superior", tornando-se, assim, um pioneiro do cinema educativo no Brasil (LEMME, 1988c, p. 56).

Entre 1950 e 1960, atuou como professor de História e Filosofia da Educação, permanecendo no serviço público até 1960, quando se aposentou. Entre 1974 e 1982, Lemme manteve a prática de enviar cartas aos principais jornais diários do Rio de Janeiro, o Jornal do Brasil e O Globo. Segundo a sua orientação, as missivas poderiam ser divulgadas, caso fossem "consideradas úteis e oportunas", o que de fato ocorreu: todas as cartas foram publicadas, como informa o próprio Lemme (1988b, p. 189).

A narrativa de suas atuações, aqui sumariada, revela a imagem de um profissional que, apesar das dificuldades decorrentes de uma opção política pouco comum na época, tornou-se vitorioso, sendo reconhecido pela geração de educadores posterior à sua. Essa afirmação é atestada pela homenagem recebida por Lemme em 1982 na II Conferência Brasileira de Educação, quando fez um pronunciamento em defesa de suas teses acerca da relação entre educação e sociedade, mostrando que os problemas educacionais do país eram de natureza política e social, situados acima da esfera estritamente pedagógica. Também atesta o sucesso de Lemme na atualidade a apreciação de Paiva (2004, p. 17), para quem o autor foi o representante de um pensamento diferenciado, um "precursor da intelectualidade independente", que assumiu solitariamente a luta contra os ditames de um "país politicamente truculento e primário".

A narrativa autobiográfica de Paschoal Lemme atribui a ele um papel privilegiado no interior de um drama por ele mesmo desenhado, no qual se enfrentam os preceitos liberais e os princípios marxistas relativos aos destinos da educação e do país. Nesse cenário, Lemme torna-se um personagem quase mítico, o obstinado "intelectual de esquerda", como diz Paiva (2004, p. 17), o homem de posição minoritária que luta incansavelmente para defender suas teses. Após tantas batalhas, Lemme torna-se finalmente um intelectual destacado dos demais, o que the confere respeito e prestígio perante a audiência que o lê nos anos de 1980.

A narrativa de Lemme reforça o sentimento de confiança nele mesmo. Contribui para o mesmo objetivo o fato de ele ter ocupado cargos de destaque na administração pública, mesmo não compartilhando ideais idênticos aos de seus superiores. Sua proximidade com os escolanovistas, em especial Fernando de Azevedo e Anísio Teixeira, opera como evidência de ser ele um homem em quem se pode confiar, alguém que não inspira temor, mesmo quando apresenta posicionamentos políticos e educacionais divergentes. Considerando a estratégia de vincular as qualidades da pessoa a seus atos e ideias, pode-se dizer também que tais posicionamentos, mesmo sendo divergentes, podem inspirar confiança, não temor.

$\mathrm{Na}$ autoimagem desenhada por Paschoal Lemme, pode-se identificar também a "argumentação pelo sacrifício", o que, segundo Perelman e Olbrechts-Tyteca (2005, p. 282), constitui uma estratégia discursiva em que o orador assume função semelhante à de um mártir, pessoa que oferece sua vida em prol de realizações benéficas à 
coletividade. O valor daquilo pelo que se faz um sacrifício é medido pela intensidade do próprio sacrifício. Assim, as teses políticas e educacionais de Lemme assumem grandeza ímpar por serem defendidos por um homem que se submeteu a atuar sob o comando de líderes de quem discordava, e que foi injustiçado, sendo preso em nome de suas crenças e de sua vocação. Como não confiar em um homem com tais qualidades? Como não admirar os ideais que sustentam atos tão grandiosos?

\section{As teses do missionário}

Paschoal Lemme afirma ter sido norteado, durante toda a sua vida profissional, pelo valor da coisa pública, pelo bem da nação e de seu povo. Em consonância com sua vocação, sempre sustentou a necessidade de transformar a educação brasileira em prol da parcela da população que historicamente tem menos acesso à escolarização. Tais ideias eram, até certo ponto, comuns aos demais educadores de sua época que pleiteavam mudanças no sistema de ensino, os integrantes do movimento escolanovista. Lemme, no entanto, diferenciava-se deles por assumir convicções que declara fundamentadas no marxismo-leninismo, filosofia política que considerava a "verdadeira interpretação do universo", bem como "do homem e de sua vida em sociedade" (LEMME, 2004b, p. 163-164).

Apoiado nesses princípios, Lemme defende a tese de que somente a transformação radical das bases econômicas e sociais de um país pode levar a transformações no âmbito escolar. Ao adotar essa concepção, colocou-se em posição absolutamente contrária à dos demais defensores da renovação educacional, os quais, segundo descreve, acreditavam na renovação do ensino como meio imprescindível para produzir alterações na esfera mais ampla da sociedade. Embora discordando dos escolanovistas, como já foi mencionado, Lemme sempre colaborou com as suas medidas administrativas, o que ele mesmo justifica pela necessidade de exercer a sua vocação e cumprir a sua missão.

Como se pode notar, Lemme opera com duas noções para analisar o processo que une educação e sociedade: os "fatores econômicos" e os "fatores educacionais", situados em polos opostos e inconciliáveis. Esse modo de raciocinar revela o que Perelman e Olbrechts-Tyteca (2005, p. 500) denominam "dissociação de noções", estratégia argumentativa que se encontra, por exemplo, em discursos que promovem a distinção entre corpo e alma, sujeito e objeto, realidade e aparência etc. Os termos da dissociação são alocados em pares antitéticos, os quais, no decorrer do discurso, são hierarquizados, assumindo um deles predominância sobre o outro.

A narrativa de Lemme sustenta a prioridade dos "fatores econômicos" ante os "fatores educacionais", expressando assim um dualismo que o autor caracteriza como decorrente da filosofia marxista. Torna-se, portanto, inviável promover mudanças na educação escolar antes que se efetivem profundas transformações na vida econômica do país. Segundo a apreciação do autor, os escolanovistas, ao defenderem posição oposta, acreditando nas reformas no ensino como causadoras de alterações na sociedade, aderiam ao primeiro termo da referida dicotomia, os "fatores educacionais", em detrimento do segundo, os "fatores econômicos", incorrendo, por isso, em profundo equívoco teórico com evidentes consequências práticas.

O caráter polêmico da tese de Lemme, posicionando as transformações 
educacionais como dependentes dos fatores estruturais, permite que se compreenda a necessidade de abordar com cautela as paixões da audiência, conduzindo os leitores ao sentimento de confiança no narrador, conforme foi identificado anteriormente neste trabalho. Além disso, o vínculo com o marxismo sempre foi visto por muitos como algo temeroso, e o próprio Lemme (1988c, p. 214) admite que, no Brasil, o partido Comunista era uma entidade de caráter "secreto e misterioso", em nada condizente com os princípios democráticos da "discussão livre" e da "liberdade de pensamento e ação". A narrativa do autor é enfática em destacar sua contrariedade a esses procedimentos, mostrando-se sempre favorável à democracia.

Mais uma vez, depreende-se das memórias de Lemme que não há motivos para temê-lo e que nele se pode confiar; afinal, as suas relações com aquela agremiação política foram estabelecidas somente após o ano de 1945, quando o Partido esteve, por curto período de tempo, na legalidade. Por tudo o que realizou como profissional, na condição de comunista que sobreviveu ao lado de pessoas que acreditavam em ideias diferentes das suas, o orador transmite ao leitor a imagem de um homem isento de paixões negativas, dotado de ideais que não ameaçam e não despertam ira; pelo contrário, almejam a paz e a tranquilidade na ordem social, o que se pode conquistar por meio de ações serenas e sensatas, mesmo em situações adversas.

No prefácio da primeira edição das memórias de Paschoal Lemme, Houaiss (1988, p. 14) afirma ser impossível não notar que daquela obra "emerge paixão". De fato, o narrador não apenas exprime paixões positivas acerca de sua profissão e de suas ideias, como também imprime - ou busca imprimir - nos leitores a paixão que pode suscitar disposições favoráveis a si mesmo e a seus posicionamentos políticos e educacionais. Sua autobiografia transmite "tranquilidade", paixão definida por Aristóteles (Retórica, II 1380a5) como contrária à "cólera"; a tranquilidade produz o "apaziguamento" da raiva, remetendo à sensação de calma, serenidade, inexistência de conflitos.

As narrativas de trajetórias de vida, que enaltecem atributos pessoais em meio a dificuldades sofridas e sucessos alcançados, usualmente constituem uma "metáfora teatral", definida por Billig (2008, p. 56) como o recurso discursivo em que o orador apresenta os episódios de sua vida como se fizessem parte de uma peça de teatro, a qual, sendo de sua própria autoria, tem por objetivo posicionar os seus atos no centro do enredo. Nesses casos, a persuasão - sustentada pela confiança que o narrador inspira na audiência - depende muito da forma como são expostos os acontecimentos: é essencial que o discurso descreva uma trajetória sequencialmente ordenada, a fim de enfatizar o sentido de continuidade e a noção de unidade; deve-se evitar que o percurso descrito soe confuso, pois a fragmentação é vista socialmente como indício de desordem, de fraca articulação psicológica (idem, p. 61-62).

As memórias de Paschoal Lemme, compostas por cinco volumes temáticos que abrangem sua vida pessoal e profissional, além de reflexões sobre alguns acontecimentos históricos e documentos de sua autoria, atendem perfeitamente a esses requisitos; cada volume é dividido em capítulos que exibem minuciosamente a ascensão do autor em busca de exercer sua vocação e cumprir sua missão, elaborando, pouco a pouco, a imagem de um homem obstinado e persistente. A figura do herói mítico vai sendo forjada em episódios recheados de problemas, dentro de uma cena adversa à concretização de seus ideais messiânicos; apesar do contexto adverso, o protagonista não esmorece, pois 
as suas qualidades e habilidades superam todos os entraves.

\section{A retórica de uma geração}

Embora Paschoal Lemme tenha publicado sua narrativa memorialística na década de 1980, certos traços de seu discurso coincidem com o modo de expressão típico de homens que se destacaram na vida cultural brasileira no início daquele século. Segundo Pécaut (1990, p. 6), tais homens - genericamente denominados intelectuais - eram oriundos das elites e portadores de diplomas de cursos superiores, o que os diferenciava da massa da população. Eram vistos como os únicos capazes de conduzir a "formação da sociedade", colocando-se a serviço do conhecimento, em sintonia com a "realidade nacional". O intelectual era aquele que se posicionava "à altura da construção da nação", portador da "identidade nacional", verdadeiro "detentor do saber relativo às leis da evolução histórica". Apesar de apresentarem entre si diferenças quanto a idade, ideias e objetivos, suas características comuns permitem classificá-los como pertencentes a uma geração (GOMES,1996, p. 38).

Bastos (2003, p. 160-161) esclarece que os membros de uma geração possuem uma "fisionomia comum", diferente de outras gerações. Uma geração é composta pela distinção entre indivíduos "seletos" e "vulgares", cabendo aos primeiros dirigir os segundos, realizando um empreendimento considerado fundamental para a consolidação da sociedade a que pertencem. Os seletos, que são instituídos ou instituem a si mesmos como melhores, semeiam exemplos a serem seguidos, no que tange ao aprimoramento do povo; detentores de uma cultura invulgar e de conhecimentos ilustrados, concebem as suas próprias vidas como um ofício, uma "missão" que lhes impõe a responsabilidade de transformar a realidade vigente, tendo por meta alcançar um futuro próspero para todos.

A geração que se constituiu no Brasil nas primeiras décadas do século $X X$ foi marcada pela defesa da organização e modernização do país, sendo formada por intelectuais questionadores das "concepções tradicionais" e das instituições fundadas pela República, tidas como alheias à realidade social devido ao predomínio das oligarquias. A formação e a atuação profissional de Paschoal Lemme ocorreram naquele período, quando se buscava a "gênese do Brasil Moderno", expressão que, segundo Lahuerta (1997, p. 93), qualifica aquele momento da história como palco da introdução de costumes, métodos, ideias e diagnósticos que passaram a orientar toda uma geração.

Os traços típicos daquela geração sobreviveram até a década de 1940, sendo compartilhados por escritores, professores, médicos, advogados e outros profissionais, membros da nova elite brasileira pautada pela tarefa de criar um "novo povo" e uma "nova cultura”, a fim de assegurar a unidade do país (PÉCAUT, 1990, p. 15). Martins (1986, p. 12) considera que a cultura e a política eram os setores de atuação privilegiados por aquele ímpeto modernizador cujo intuito era questionar os padrões tradicionais vigentes. Embora articulado por um pequeno número de intelectuais, o movimento modernista exprimia essas características, representando a força inicial que indicava o caminho da renovação do país. A Semana de Arte Moderna, realizada em 1922 na cidade de São Paulo, é ilustrativa das ações empreendidas por intelectuais que buscavam uma nova configuração cultural, firmando assim as características daquela geração.

Pécaut (1990, p. 21) entende que, durante os primeiros anos da década de 1920, os intelectuais reivindicavam uma "ciência do social", sugerida por alguns escritores da 
época como uma "artimanha" para que as suas vozes fossem ouvidas pelo governo. Havia um anseio incessante por transformar o "artista em intelectual", o que era motivado pela crença no poder da ciência para orientar a "administração científica dos homens e da natureza" (LAHUERTA, 1997, p. 94). O positivismo e o liberalismo eram os referenciais em voga nos círculos intelectuais da época, ainda que fossem adotados de modo seletivo em alguns momentos e, em outros, de modo "extravagante" (MARTINS, 1986, p. 9).

Diante das conturbações próprias de uma era de mudanças, os homens daquela geração enfrentaram uma crise de "identidade social" que os impulsionou a "problematizar" radicalmente seu papel na sociedade (LAHUERTA, 1997, p. 94). Para Martins (1986, p. 13-14), tal crise deveu-se ao fato de aqueles intelectuais, mesmo compartilhando a esperança de renovar a nação, terem tomado consciência dos limites da transformação pretendida; o "atraso do país, a estreiteza dos espíritos" e os obstáculos da política geraram um "sentimento de isolamento e impotência". Em sua luta para modernizar o país, sentiam-se solitários, isolados diante da sociedade, impotentes para dar andamento às metas ambiciosas de sua missão.

Esse parece ter sido o caso de Paschoal Lemme, como se pode apreender da análise de sua narrativa autobiográfica. Suas memórias indicam que ele também vivenciou o que Martins (1986, p. 14) denomina de "ambivalência", sentimento comum àqueles que assumiam um posicionamento otimista diante dos fins que almejavam, mas eram acometidos pelo pessimismo quanto aos meios para alcançá-los. É certo, também, que, juntamente com os demais integrantes daquela geração, Lemme empenhou-se com afinco na busca por definir sua identidade social, assumindo um caráter missionário.

Lahuerta (1997, p. 94-95) analisa que a ideia de missão já estava presente nos meios intelectuais desde o início da República, mas foi no decorrer dos anos de 1920 que adquiriu novos significados e maior abrangência, tornando-se o messianismo o principal traço daquela geração. Martins (1986, p. 16) acrescenta que a construção de uma imagem messiânica implicava atribuir àquele grupo de intelectuais o status de "iluminados", de verdadeiros "heróis modernizadores" capazes de cumprir a "missão" de transformar um país atrasado, doente e analfabeto em uma nação moderna, sadia e alfabetizada. A elaboração dessa autoimagem permitiu justificar as ações daqueles homens, cujas ideias foram então posicionadas como condutoras das aspirações do povo brasileiro.

O emprego desse recurso pelos homens daquela geração - incluindo Lemme nesse rol, como se conclui pela análise de suas memórias - não tinha o intuito de levá-los a ocupar o espaço de alguma classe social, nem de autorizá-los a falar "em nome da nação", como bem assinala Martins (1986, p. 16); o que os movia era a intenção de conquistar o reconhecimento de sua condição de intelectuais e ver legitimada a sua "liderança moral", colocando em primeiro plano a "organização nacional". Não buscavam promover uma "revolução", mas "organizar um país real" a partir de preceitos científicos, visando assim resgatá-lo do atraso histórico responsável pelo "desencanto" com a política. Muitos deles foram conduzidos por uma "visão tecnocrática da mudança social" em que se incluía a proposta de reformar a sociedade por meio da reforma da educação e do ensino público, o que resultaria na "criação dos homens e técnicos" necessários ao país.

Era precisamente esse o ambiente vivido por Paschoal Lemme, segundo se lê em 
suas memórias. Lemme expressa muitas das ideias que Martins (1986, p. 16) considera típicas dos intelectuais daquela época, homens que se viam como pertencentes à fatia "civilizada" e "enraizada" da sociedade, convictos da relevância de sua contribuição à mudança das estruturas sociais: o descontentamento com as estruturas "rígidas e atrasadas" do país, o desejo de construir uma nação moderna lutando contra a "estreiteza dos espíritos". Nesse mesmo ambiente, eventos como a criação da ABE e as reformas do ensino comandas por Fernando de Azevedo, Anísio Teixeira e outros escolanovistas nos anos de 1920 e 1930 constituíram respostas aos problemas educacionais do Brasil.

Paschoal Lemme acompanhou ativamente todos esses eventos, embora contrariando a visão hegemônica que almejava mudar a sociedade por meio da escola. Acompanhou também o conflito ocasionado pela tendência centralizadora de Getúlio Vargas que, a partir de 1930, com a criação do Ministério da Educação e Saúde Pública, passou a tutelar todas as iniciativas na área educacional. A margem de influência dos intelectuais foi então sensivelmente reduzida, o que tornou sua missão modernizadora dependente de alianças com o Estado, instituído como representante único do interesse geral da nação. Os intelectuais foram dispersados em várias vertentes políticas - liberais, católicos, fascistas e comunistas -, o que os distanciou ainda mais de sua função missionária (MARTINS, 1986, p. 18-19). Por fim, o Estado Novo, vigente entre 1937 e 1945, sepultou seus anseios identitários (idem, p. 22).

\section{Considerações finais}

As obras dos intelectuais do começo do século XX sobreviveram ao tempo, deixando como contribuição às gerações seguintes um legado discursivo singular, constituído pela apresentação bem articulada de seus feitos e ideias, por uma narrativa que os apresenta como dotados de capacidades ímpares, protagonistas do drama vivido pelo país, e por argumentos que enfatizam seu ideal missionário construído na forma de uma cena teatral - traços que os elevaram à condição de mitos de uma época, faróis acessos em direção ao futuro, exemplos de conduta cívica e fidelidade a um ideal.

Como foi assinalado na seção introdutória do presente trabalho, a análise retórica não tem o intuito de elaborar juízos de valor sobre os temas a que se dedica, mas compreender o orador e seu discurso, de modo a propiciar hipóteses acerca de seus efeitos persuasivos sobre a audiência a que se destina sua argumentação. Nesse aspecto, vale observar que, até a publicação de suas memórias, Paschoal Lemme não figurava no panteão dos intelectuais que marcaram a vida cultural brasileira no início do século passado. A publicação de seu relato memorialístico parece cumprir a meta comum a toda narrativa autobiográfica: permitir que o autor sirva de norte para as novas gerações, o que é especialmente relevante quando não se apresentam soluções consensuais acerca dos dilemas contemporâneos.

A situação dos educadores da década de 1980, a audiência visada por Lemme, ainda catalisa a atenção dos pesquisadores da área; pelo que se registra até o momento, é possível dizer que se tratou de uma época permeada por diversas alternativas teóricas e práticas, em grande parte devido às circunstâncias políticas do país - a exaustão causada por duas décadas de ditadura militar, os movimentos de resistência organizados por vários setores da sociedade civil, incluindo as associações de educadores, e a abertura para novas ideias provindas do exterior. 
As pautas do escolanovismo ainda estavam presentes na memória de muitos teóricos e ativistas. Segundo Saviani (2004, p. 186), quando se realizou a I Conferência Brasileira de Educação, em 1980, "o ideário da Escola Nova havia se tornado hegemônico e, nessa condição, havia ganhado a cabeça dos professores". Foi motivado por essa percepção que Saviani apresentou naquele evento a metáfora da "curvatura da vara", mais tarde celebrizada em seu livro Escola e democracia; sua intenção era "inverter a posição dominante que considerava a Escola Nova portadora de todas as virtudes e nenhum vício em contraposição à escola tradicional, considerada portadora de todos os vícios e de nenhuma virtude".

Tal intervenção ilustra o quadro pouco consensual em que se moviam os profissionais da educação naquele momento. Como foi mencionado neste trabalho, Paschoal Lemme foi homenageado dois anos depois, na II Conferência Brasileira de Educação, fazendo um contundente pronunciamento em defesa de suas teses de natureza marxista sobre a relação entre as esferas social e educacional. Somando-se este fato à publicação de sua narrativa memorialística, é plausível considerar que Lemme buscava ocupar um espaço nas disposições intelectuais e afetivas dos educadores, oferecendo suas ideias e sua experiência profissional para iluminar os caminhos da educação brasileira.

\section{Referências}

ALBERTI, Verena. Ouvir e contar textos em história oral. Rio de Janeiro: FGV, 2004.

AMADO, Janaína; FERREIRA, Moraes Marieta. Usos e abusos da história oral. 8. ed. Rio de Janeiro: FGV, 2006.

ARISTÓTELES. Retórica. Tradução Edson Bini. São Paulo: Edipro, 2011.

BASTOS, Elide Rugai. A revista Cultura Política e a influência de Ortega y Gasset. In: BASTOS, Elide Rugai; RIDENTI, Marcelo; ROLLAND, Denis (Orgs.). Intelectuais: sociedade e política. São Paulo: Cortez, 2003.

BILLIG, Michael. Argumentando e pensando: uma abordagem retórica à psicologia social. Tradução Vera Lúcia Mello Joscelyne. Petrópolis: Vozes, 2008.

BOURDIEU, Pierre. A ilusão biográfica. In: AMADO, Janaína; FERREIRA, Marieta Moraes (Orgs.). Usos e abusos da história oral. 8. ed. Rio de Janeiro: FGV, 2006.

BRANDÃO, Zaia. Paschoal Lemme. In: FÁVERO, Maria de Lourdes Albuquerque; BRITTO, Jader de Medeiros (Orgs.). Dicionário de educadores no Brasil: da Colônia aos dias atuais. 2. ed. Rio de Janeiro: UFRJ/MEC/INEP/COMPED, 2002.

. A intelligentsia educacional: um percurso com Paschoal Lemme por entre as histórias e memórias da Escola Nova no Brasil. Bragança Paulista: EDUSF, 1999.

GOMES, Ângela de Castro. História e historiadores: a política cultural do Estado Novo. Rio de Janeiro: FGV, 1996.

HOUAISS, Antônio. Prefácio. In: LEMME, Paschoal. Memórias: infância, adolescência, mocidade. São Paulo: Cortez, 1988.

LAHUERTA, Milton. Os intelectuais e os anos 20: moderno, modernista, modernização. In: LORENZO, Helena Carvalho; COSTA, Wilma Peres (Orgs.). A década de 1920 e as origens do Brasil moderno. São Paulo: UNESP, 1997.

LE GOFF, Jacques. História e memória. Tradução Irene Ferreira, Bernardo Leitão, 
Suzana Ferreira Borges. 5. ed. Campinas: UNICAMP, 2003.

LEMME, Paschoal. Memórias: estudos de educação e destaques da correspondência. 2. ed. Brasília: INEP, 2004a.

. Memórias: estudos de educação, participação em conferências e congressos; documentos. 2. ed. Brasília: INEP, 2004b.

. Memórias: infância, adolescência, mocidade. São Paulo: Cortez, 1988a.

. Memórias: reflexões e estudos sobre problemas da educação e ensino. Perfis:

Anísio Teixeira, Fernando de Azevedo, Heloísa Alberto Torres, Humberto Mauro, Sousa Silveira. São Paulo: Cortez, 1988b.

Cortez, 1988c.

Memórias: vida de família, formação profissional, opção política. São Paulo:

LEVI, Giovanni. Usos da biografia. In: AMADO, Janaína; FERREIRA, Marieta Moraes (Orgs.). 8. ed. Usos e abusos da história oral. Rio de Janeiro: FGV, 2006.

MARTINS, Luciano. A gênese de uma intelligentsia: os intelectuais e a política no Brasil, 1920-1945. Tradução Yamara Villalobos. Revista Brasileira de Ciências Sociais, Paris, v. 2, n. 4, p. 1-25, jun. 1986.

PAIVA, Vanilda. Prefácio. In: LEMME, Paschoal. Memórias: estudos de educação e destaques da correspondência. 2. ed. Brasília: INEP, 2004.

PÉCAUT, Daniel. Os intelectuais e a política no Brasil: entre o povo e a nação. Tradução Maria Júlia Goldwasser. São Paulo: Atica, 1990.

PERELMAN, Chaïm; OLBRECHTS-TYTECA, Lucie. Tratado da argumentação: a nova retórica. Tradução Maria Ermantina de Almeida Prado Galvão. 2. ed. São Paulo: Martins Fontes, 2005.

REALE, Giovanni. História da filosofia antiga. V. Léxico, índices, bibliografia. 2. ed. Tradução Henrique C. de Lima Vaz e Marcelo Perine. São Paulo: Loyola, 2001.

SAVIANI, Dermeval. Setenta anos do Manifesto e 20 anos de Escola e democracia: balanço de uma polêmica. In: XAVIER, Maria do Carmo (Org.). Manifesto dos pioneiros da educação: um legado educacional em debate. Rio de Janeiro: FGV, 2004.

SBRANA, Roberta Aline. Análise retórica de narrativas memorialísticas. Educação e Filosofia, Uberlândia, 2016 (no prelo).

SOUZA, Aline Vieira. As paixões no discurso educacional de Cecília Meireles. Educação e Filosofia, Uberlândia, 2016 (no prelo).

THOMSON, Alistair; FRISCH, Michael; HAMILTON; Paula. Os debates sobre memória e história: alguns aspectos internacionais. In: AMADO, Janaína; FERREIRA, Marieta Moraes (Orgs.). 8. ed. Usos e abusos da história oral. Rio de Janeiro: FGV, 2006.

ROBERTA ALINE SBRANA é pedagoga e Mestre em Educação pela Faculdade de Filosofia, Ciências e Letras de Ribeirão Preto (USP); cursa o doutorado em Educação Escolar na Faculdade de Ciências e Letras de Araraquara (Unesp) com subsídio de bolsa Fapesp. Endereço: Rua João Cruz Novaes, 779 - Bairro Vila Monteiro - 14200-000 - São Simão/SP Brasil

E-mail: any.bobys@hotmail.com 
MARCUS VINICIUS DA CUNHA é Doutor em Educação pela USP e Livre Docente em Psicologia da Educação pela Unesp. É docente do curso de Pedagogia e do Programa de Pós-Graduação em Educação da Faculdade de Filosofia, Ciências e Letras de Ribeirão Preto (USP); é colaborador do Programa de Pós-Graduação em Educação Escolar da Faculdade de Ciências e Letras de Araraquara (Unesp) e pesquisador do CNPq.

Endereço: Rua Breno Vieira de Souza, 377 - 14090-620 - Ribeirão Preto/SP - Brasil

E-mail: mvcunha2@hotmail.com

Recebido em 12 de fevereiro de 2016.

Aceito em 25 de outubro de 2016. 